\title{
THE ASCUS APEX IN LICHENIZED FUNGI IV. BAEOMYCES AND ICMADOPHILA IN COMPARISON WITH CLADONIA (LECANORALES) AND THE NON-LICHENIZED LEOTIA (HELOTIALES)*
}

\author{
Rosmarie HONEGGER $\ddagger$
}

\begin{abstract}
This comparative investigation on ascus fine structure and function substantiates the findings of Chadefaud (1960) and his coworkers indicating a close taxonomic relationship between the Baeomycetaceae and Leotia, a non-lichenized member of the Helotiales, rather than between the Baeomycetaceae and the Cladoniaceae and other members of the Lecanorales. Besides the distinct differences in ascus structure and function, cytological divergences were noted between the Baeomycetaceae and Leotia on one hand, and Cladoniaceae on the other. The occurrence of glycogen in the Baeomycetaceae and Leotia, but not in the Cladoniaceae and other members of the Lecanorineae, and the differences in phycobiont preference and thus in the mycobiont-phycobiont contact in the Baeomycetaceae and Cladoniaceae were discussed.
\end{abstract}

\section{Introduction}

Natural groups of ascomycetes at the rank of order are grouped in modern taxonomic concepts on the basis of ascus structure and function. In a preliminary survey on the functional ascus types within the largest order of lichenized fungi, the Lecanorales, a considerable heterogeneity was noted even at the level of suborders sensu Henssen \& Jahns (1973) in ascus structure and function (Honegger 1982b). Some of the lichen families with apothecia-bearing mycobionts and unitunicateinoperculate asci were classified within the Lecanorales mainly because they are lichenized, rather than on the basis of the characteristics of ascomycete taxonomy (Hertel 1970). Or, as stated by Santesson (1954), 'in no other group of plants is the taxonomic work carried out more carelessly than in lichenology'. Within the last 20 years many groups of lichenized fungi have been revised on the basis of ascocarp ontogeny and/or ascus structure and function, and many interesting and noteworthy attempts have been made towards a natural classification of the lichen-forming groups and their inclusion with all known ascomycetes (Luttrell 1951, Henssen \& Jahns 1973, Poelt 1974, Barr 1976). Despite all this progress, various fundamental problems in classification remain, and the taxonomic position of many different groups remains unclear (Hawksworth 1978).

One lichen family which differs considerably from all others classified within the same suborder is the Baeomycetaceae, comprising the genera Baeomyces and Icmadophila. In recent taxonomic treatments a close relationship between the Baeomycetaceae and the Cladoniaceae has been supposed. Baeomyces and Icmadophila were either included as genera within the Cladoniaceae (Ozenda \& Clauzade

^III in Lichenologist 14: 205-217 (1982).

¥Cytology Department, Institute of Plant Biology, University of Zürich, 8008 Zürich, Switzerland. 
1970), or the Baeomycetaceae were classified close to the Cladoniaceae (Poelt 1974, Henssen \& Jahns 1973, Barr 1976). Morphological similarities in vegetative and generative structures may be observed in both groups. Both the Cladoniaceae and Baeomycetaceae form vertical and horizontal thalli and the similarities in external ascocarp morphology are most obvious (Fig. 1C, E). However, in comparative investigations of ascocarp ontogeny significant differences were noted between the Baeomycetaceae and the Cladoniaceae (Letrouit-Galinou 1966, 1968, Jahns 1970, Jahns \& Smittenberg 1970, Jahns \& Horst-Iwema 1972). A fundamental difference between the Baeomycetaceae and Cladoniaceae was noted in comparative investigations of ascus structure and staining properties in various lichenized and non-lichenized fungi by Chadefaud and his coworkers. Magne (1946) observed a very simple, non-amyloid ascus type ('type fruste') in Baeomyces, but a strongly amyloid apical dome and amyloid outermost wall layer in the asci of Cladonia. Le Gal $(1946 a, b)$ and Chadefaud $(1960,1973)$ pointed out that the ascus type of the Baeomycetaceae closely resembled the ascus of Leotia and allied genera, all non-lichenized members of the Geoglossaceae/Helotiales. Consequently, Chadefaud (1960) transferred the Baeomycetaceae from the Lecanorales to the Helotiales. In a survey on ascus structure and staining properties in lichens Letrouit-Galinou (1973) described the ascus of the Baeomycetaceae as 'type léotien' among the 'cas particuliers', whereas the completely different ascus of Cladonia was interpreted as an intermediate form, linking the 'type eu-archaeascé ' (corresponding to the Lecanora-type of Honegger 1978a, b) with the 'type post-archaeascé' (Peltigera-type of Honegger 1978b).

The significance of ascus structure and function for the classification of the lichenized ascomycetes has been underestimated by many lichen taxonomists for too long a period. This might be one reason why the findings of Chadefaud and his coworkers concerning the Baeomycetaceae and their taxonomic position received little attention. In the present investigation ascus structure and function of the lichenized genera Baeomyces, Icmadophila and Cladonia are compared with the non-lichenized Leotia using light microscopic ( $L M$ ) and transmission electron microscopic (TEM) techniques. First approaches to the fine structure of the ascus apex in Leotia, Baeomyces and Cladonia were made by Bellemère (1977) and Honegger $(1977,1978 a)$. Since these data are either based on poorly preserved material, or not easily accessible, a re-investigation and re-presentation of the problem is required.

FIG. 1. LM preparations of ascocarps and asci. A, Leotia lubrica, a non-lichenized member of the Helotiales; $\times 6 . \mathrm{B}$, Asci after staining with Lugol's solution; no amyloid structures were detected in the wall layers of the ascus or the apical apparatus; $\times 950$. C, Baeomyces rufus, squamulose thallus horizontalis and podetia with apothecia; $\times 6$. D, Asci after staining with Lugol's solution; no amyloid structures were detected in the wall layers and the apical apparatus; $\times 950$. E, Cladonia caespiticia, thallus squamules with apothecia; $\times 20$. F, G, Asci after staining with Lugol's solution. An outer layer (ol) of the ascus wall (aw) and the apical dome (d) turned blue with iodine, whereas the ascus wall itself is non-amyloid; the material of the central part of the dome (the 'tube perioculaire ' according to Letrouit-Galinou 1973) stained more intensely than the peripheral parts of the dome; prior to ascospore release the material of the dome is stretched to a long rostrum (r) which reaches the hymenial surface; arrows point to the broken ascus wall and its amyloid outer layer; $\times 2600$. 

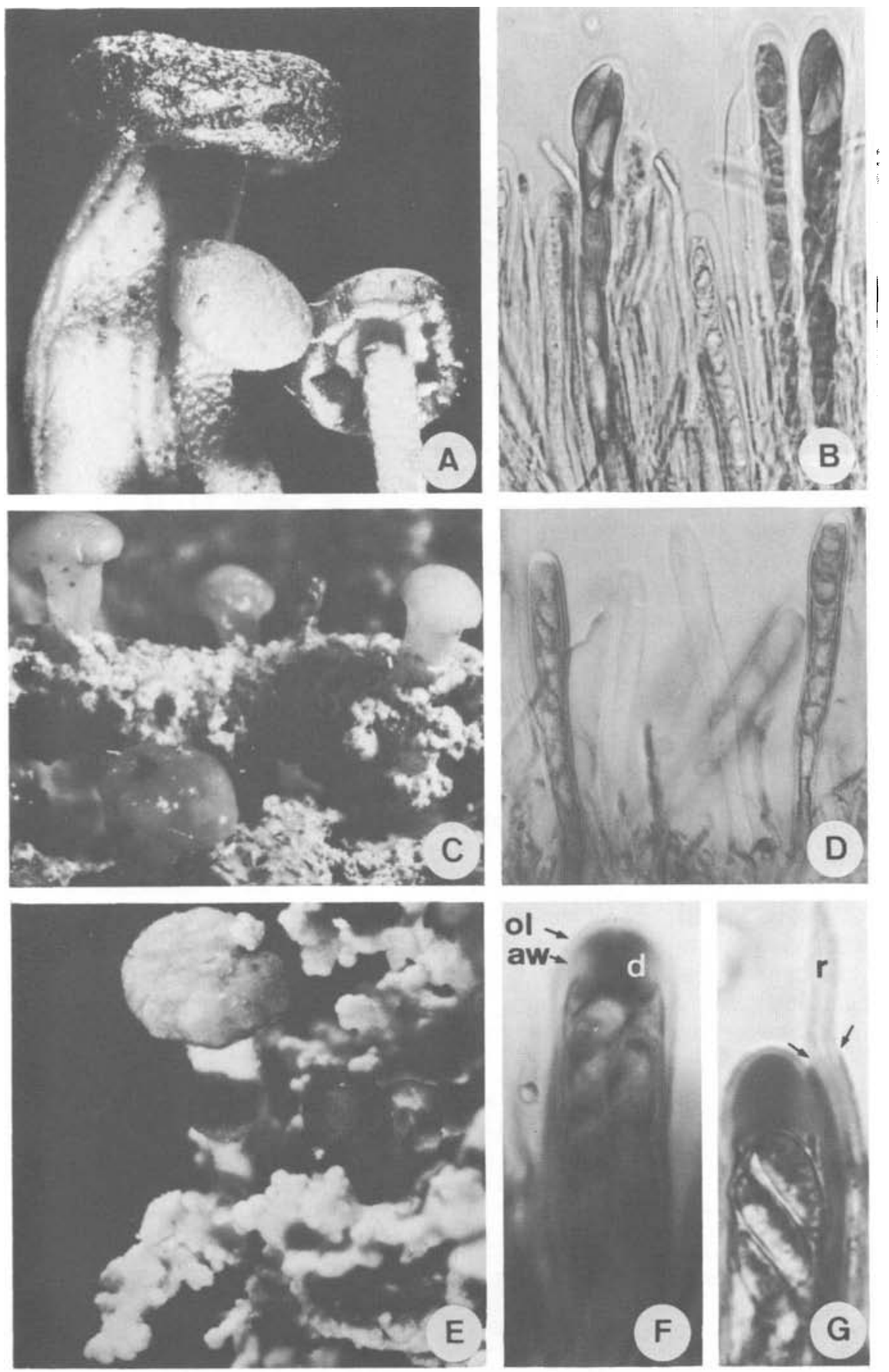

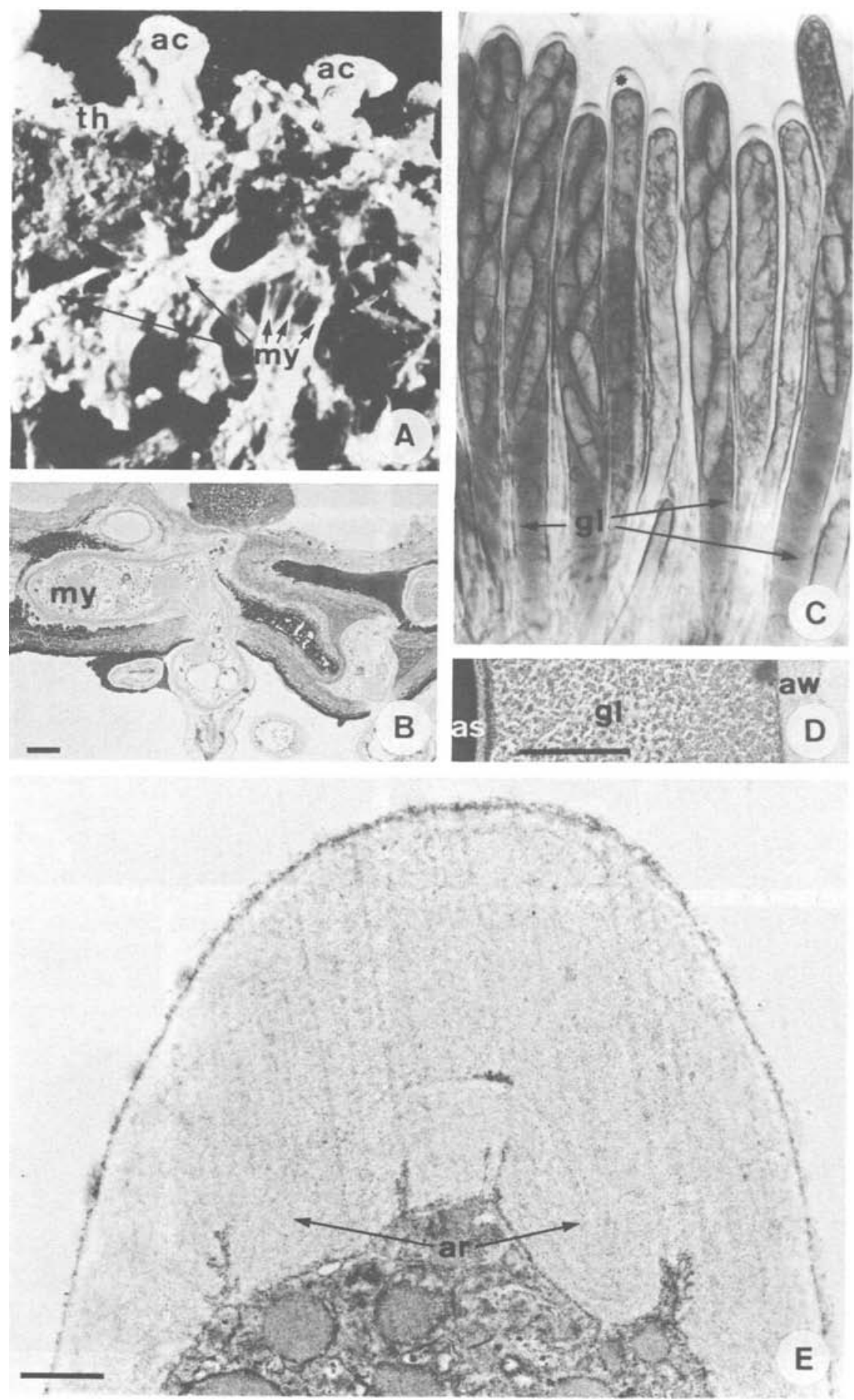


\section{Materials and Methods}

Baeomyces rufus Pers., Icmadophila ericetorum (L.) Zahlbr., Cladonia caespiticia (Pers.) Flörke and C. floerkeana ( $F_{r}$.) Flörke were freshly collected at various places in Switzerland and in Brittany, France. Fresh ascocarps of Leotia lubrica Pers. were found at different places in Switzerland by B. Irlet and E. Horak, and in Norway by P. M. Jorgensen.

Preparations for $\mathrm{LM}$ and TEM investigations were carried out as described previously (Honegger $1978 b)$. LM preparations were investigated in a Zeiss Photomikroskop 2, ultrathin sections in a Hitachi HS8 electron microscope.

\section{Results}

\section{Light microscopy}

Baeomyces rufus and Leotia lubrica. In fresh ascocarps of Baeomyces and Leotia thin-walled, apically slightly thickened asci were observed. Neither with, nor without prior treatment with potassium hydroxide were any amyloid structures detected in the asci or the hymenium after staining with Lugol's solution (Fig. 1B, D). The asci of both species are embedded in a non-amyloid, not very viscous hymenial gelatine. The apex of mature asci reaches the hymenial surface. Dehiscence occurs by a bursting of the central part of the ascus apex.

Icmadophila ericetorum. Fresh ascocarps of Icmadophila contained thin-walled, apically slightly thickened asci. Only an outermost, apically slightly thickened wall layer turned blue with iodine (Fig. 2C), whereas the main part of the ascus wall and its apical dome are non-amyloid. Pre-treatment with potassium hydroxide did not change the staining properties of either the asci, or the hymenial gelatine. Accumulations of amyloid material, probably ascus walls dissolving after ascospore release, were found in herbarium material. Dehiscence of the asci occurs by bursting of the central part of the apical dome.

Cladonia floerkeana and C. caespiticia. A massive apical dome was observed in the rather short asci of the Cladonia species investigated. The material of the dome and an outermost layer of the ascus wall turned blue after staining with Lugol's solution, whereas the main part of the ascus wall is non-amyloid (Fig. 1F, G). Pre-treatment with potassium hydroxide did not change the staining properties, but the colour reaction with iodine was seen immediately after soaking the asci in it and subsequent washing and staining; in contrast in fully developed asci it occurred rather slowly (sometimes within one or more hours, probably depending on the grade of hydration) in untreated material. The asci are embedded in a

FIG. 2. Icmadophila ericetorum, a wood- or peaty soil-inhabiting lichenized fungus. A, Section through the thallus horizontalis (th) with ascocarps (ac) and the underlaying, decaying fir wood; strands of mycobiont hyphae (my) are radiating into the degrading wood; $\times 8$. B, TEM micrograph of mycobiont hyphae (my) penetrating the lignified cell walls of their substratum (see Honegger \& Brunner 1981); $\times 4200$. C, Asci after staining with Lugol's solution; an apically slightly thickened outermost wall layer turned blue with iodine, whereas the ascus wall and the apical apparatus are non-amyloid; mature asci contain high amounts of glycogen ( $\mathrm{gl}$ ) in the remaining cytoplasm; the asterisk points on a premeiotic ascus, the developmental stage which is shown in the TEM micrograph of E; $\times 1070$. D, TEM micrograph of part of a mature ascus with high amounts of glycogen particles between the ascospores (as) and the ascus wall $a w ; \times 15000$. E, TEM micrograph of a median longitudinal section of the apex of a pre-meiotic ascus; an apical ring (ar) is protruding into the cytoplasm; $\times 11000$. Fixation: Acrolein- glutaraldehyde and osmium. Note: the bar in all TEM micrographs $=1 \mu \mathrm{m}$. 

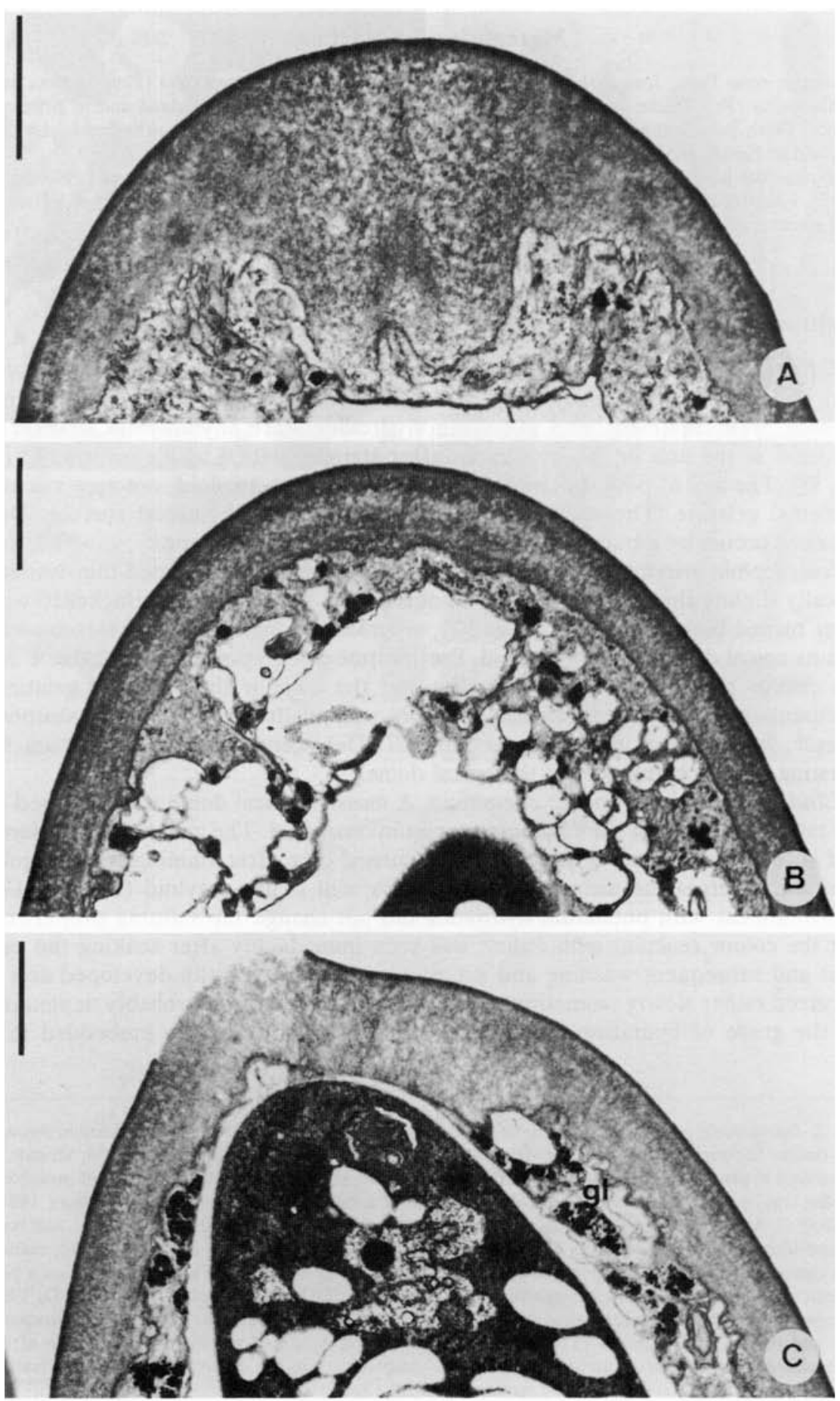
strongly amyloid hymenial gelatine. Within the amyloid dome a fine substructure, which has been described by Letrouit-Galinou (1973) as the 'tube perioculaire' was observed. A very narrow, slightly amyloid central zone of the dome is surrounded by a tube-like, strongly amyloid zone which grades into the less amyloid peripheral parts. This fine substructure of the inner zone of the ascus apex is very close to the resolution limits of the light microscope, and thus only weakly visible in Fig. 1F.

Mature asci of Cladonia are distinctly shorter than the hymenium. Prior to dehiscence the non-amyloid ascus wall and its amyloid outer layer burst at the apex. Subsequently, the material of the amyloid dome is stretched by the entering ascopores into a long beak which reaches the hymenial surface (Fig. 1G). The amyloid character of the dome is lost during dehiscence. Neither prior, nor after spore release (Fig. 1G), could any amyloid structures be detected in the rostrum. With this rostrate type of dehiscence the distance between the ascus apex and the hymenial surface is elegantly overcome.

\section{Transmission electron microscopy}

Leotia lubrica, Baeomyces rufus and Icmadophila ericetorum. A close structural similarity was observed in TEM preparations of the ascus apex in Leotia, Baeomyces and Icmadophila (Figs $2 \mathrm{E}, 3 \mathrm{~A}-\mathrm{C}, 4 \mathrm{~A}-\mathrm{C}, 5$ ). An electron-dense outer layer ('fuzzy coat') surrounds the ascus wall. No explanation was found on the ultrastructural level for the different staining properties of this outermost wall layer with iodine in Baeomyces and Leotia on the one hand, and Icmadophila on the other. Prior to meiosis an apically thickened inner layer is deposited inside the primary ascus wall. Only minor structural differences can be seen between the primary ascus wall and its inexpansible inner layer. An annular protrusion is formed in all three species. It is most visible in pre-meiotic asci (Figs 2E, 3A, 4A). At maturity the ring-shaped material of the apical apparatus seems to be reduced, probably as a result of compression due to an increase in turgor pressure, and from lytic processes. It is presumed that the centre of the annular apical thickening represents the weakest part of the ascus apex which will burst prior to ascospore release.

High amounts of glycogen in $a$ - or rosette-like $\beta$-particles were detected in all three species at various stages of ascus and ascospore development (Figs 3C, 4B, 5 ). Most obvious was the enormous accumulations of glycogen particles in the remaining cytoplasm of mature asci of Icmadophila ericetorum, which could even be seen on LM preparations (Fig. 2C, D; Chadefaud 1960). It is highly probable that this glycogen has a rôle in ascospore discharge, since its release through particle lysis might lead to a rapid increase in the osmotic pressure within the ascus. This pressure might be one amongst other unknown factors triggering the rupture of the ascus apex prior to spore release.

FIG. 3. Leotic lubrica, TEM micrographs of median longitudinal sections of the ascus apex. A, Premeiotic ascus with distinct apical ring; $\times 19200$. B, Mature ascus prior to spore discharge; the material of the ascus wall and the apical apparatus is compressed; $\times 15200 . \mathrm{C}$, At the onset of dehiscence; glycogen (gl) is seen in the remaining cytoplasm; $\times 15000$. Fixation: Acrolein-glutaraldehyde and osmium. 

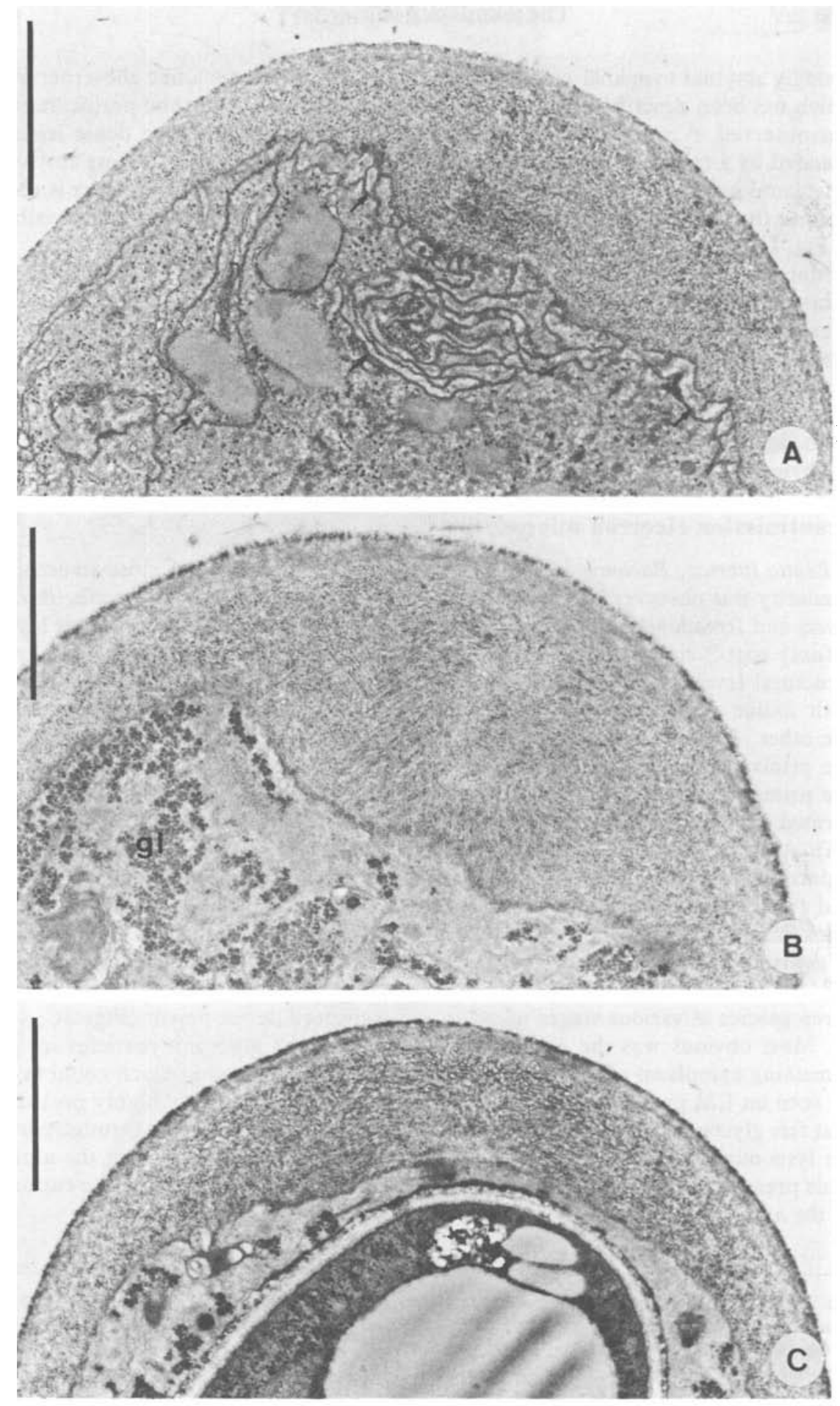
Cladonia floerkeana. An electron-dense outer wall layer of irregular thickness, corresponding to the amyloid outer wall layer observed in LM preparations, was observed around the electron-transparent ascus wall (Fig. 6). The material of the apical dome is deposited in the pre-meiotic ascus (Honegger 1978a). It is characterized by a high amount of electron-dense inclusions within an electrontransparent matrix. Accumulations of electron-dense material were observed around the basis of a pin-like, electron-transparent central zone of the dome (Fig. 6). This electron-dense material is not sharply delimited from the material of the dome. Its rôle during dehiscence is not understood. No accumulation of electrondense material was found in empty asci after spore release (Fig. 7A, B). An eversible electron-dense ring at the tip of the rostrum, as observed in the functionally bitunicate Peltigera-type ascus (Honegger 1978b), was never seen in LM or TEM preparations of Cladonia asci. In Cladonia, no gliding site was found between the ascus wall and the material of the apical dome, which is stretched during dehiscence to a long beak reaching the hymenial surface (Fig. 7A, B). Thus, Cladonia asci are functionally unitunicate in the sense of Luttrell (1951).

Glycogen particles were not detected in the asci, ascospores, paraphyses or in any other : $:$ ll type of the mycobiont.

\section{Discussion}

The present comparative investigation of ascus fine structure and function in Leotia, Baeomyces, Icmadophila and Cladonia substantiate the findings of Chadefaud $(1960,1973)$ and his coworkers indicating a close taxonomic relationship between the lichenized Baeomycetaceae and Leotia, a non-lichenized member of the Geoglossaceae (Helotiales) rather than between the Baeomycetaceae and the lecanoralean Cladoniaceae. The Leotia-type ascus, according to Chadefaud (1960) and Letrouit-Galinou (1973), is basically comparable with other ascus types observed within the Helolisles, mainly with the Pezicula-, Bulgaria-, Hypoderma- and Therrya-types described by Bellemère (1977), and with Ciboria acerina (Corlett \& Elliott 1974: Apical rings were observed in all these ascus types, some of which, howeve:, contained additional electron-dense elements. Dehiscence seems to occur in these taxa by a simple bursting of the ascus apex.

The Cladoniaceae, which were formerly supposed to be very closely related to the Baeomycetaceae, are definitely members of the Lecanorineae (Lecanorales). Their unitunicate-inoperculate ascus with an amyloid dome and rostrate type of dehiscence is clearly only a variant of the Lecanora-type ascus of Honegger $(1978 a, b)$. This particular ascus type has been observed with LM and TEM techniques in various families of the Lecanorineae and Physciineae sensu Henssen \& Jahns (1973, reviewed by Honegger 1982b). A special terminology for some of these Lecanora-type variants (e.g. 'Cladonia type', 'Physcia variant of Parmelia-

FIg. 4. Baeomyces rufus, TEM micrographs of median longitudinal sections of the ascus apex. A, Pre-meiotic ascus with an annular apical thickening; proliferations of the plasma membrane at the apex (arrows) generate the material for the ascospore delimiting membranes to be formed, $\times 22900$. B, Pre-mature ascus with annular apical thickening; glycogen (gl) is found in rosette-like $\beta$-particles in the remaining cytoplasm; $\times 24700$. C, Mature ascus shortly before ascospore release; the material of the apical apparatus is compressed; $\times 24000$. Fixation: Acrolein-glutaraldehyde and osmium. 


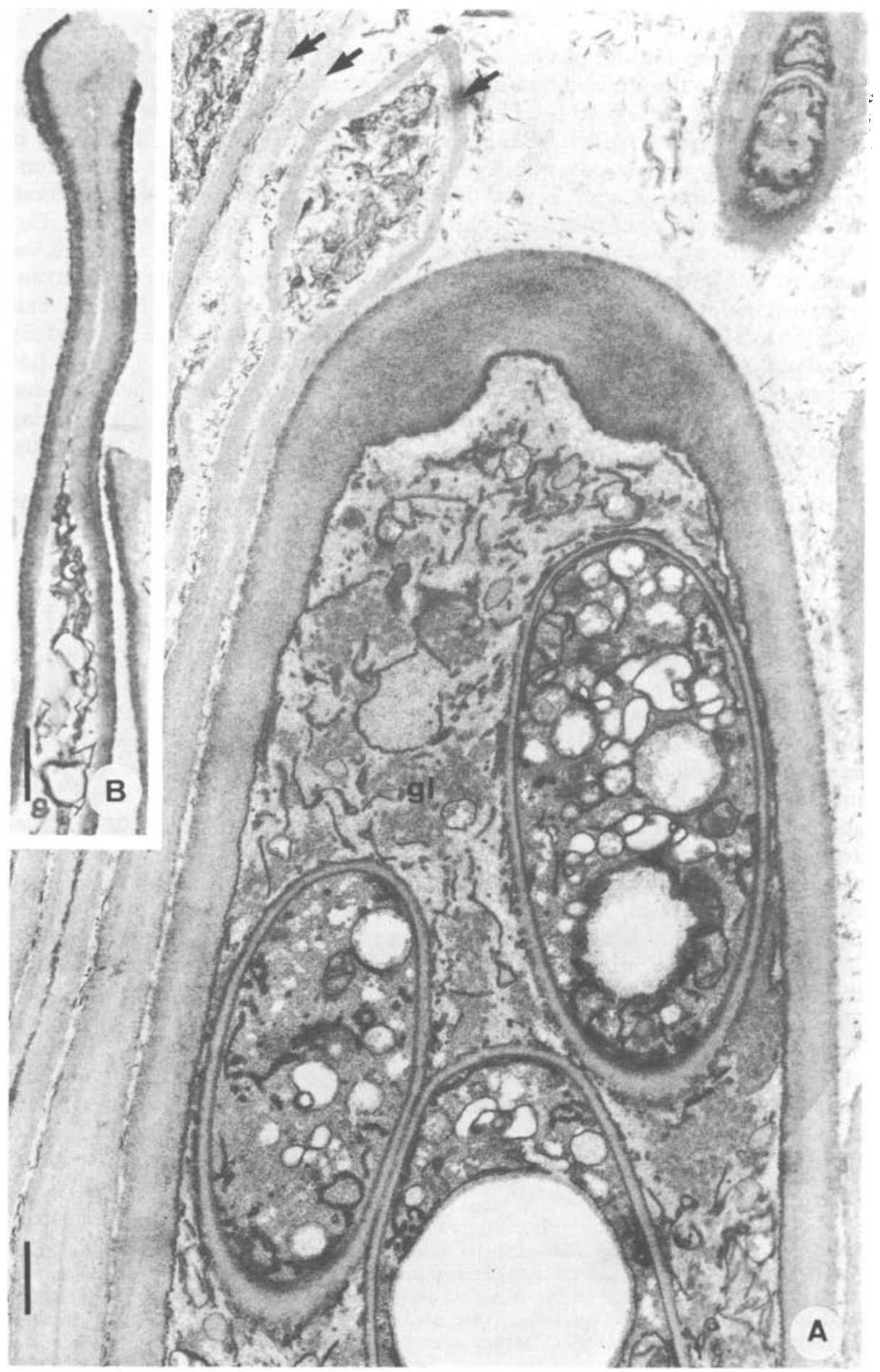


type', etc.) was proposed by Bellemère \& Letrouit-Galinou (1981). It is, however, doubtful whether such a complex terminology, which is based on ultrastructural details of partly poorly preserved material, will serve all those mycologists and lichenologists who are working within the resolution limits of the light microscope. I therefore propose to retain the Lecanora-type in its original wide sense (Honegger 1978a, $b$ ) as a functional ascus type which can be easily recognized by light microscopists.

The results of the present and former investigations (Honegger 1978a, $b$, $1982 b$ ) do not support the phylogenetic hypothesis of Letrouit-Galinou (1973) but indicate, on the basis of comparative LM studies of ascus structure and staining properties, an intermediate position of Cladonia between groups with either Lecanora-type or Peltigera-type asci. The phylogenetic position of Peltigera with its functionally bitunicate ascus and the characteristic, eversible amyloid ring at the tip of the endoascus remains unclear. An evolution of the Peltigera-type from the Lecanora-type, however, can probably be excluded (Honegger 1978a, $b$, 1980 ).

Besides the significant differences in ascocarp ontogeny (Letrouit-Galinou 1966, 1968, Jahns 1970) and ascus structure and function, two cytological divergences were noted between the Baeomycetaceae and the Cladoniaceae and other members of the Lecanorineae; their taxonomic significance cannot, however, yet be assessed since insufficient data are available. First, the occurrence of considerable amounts of glycogen in asci, ascospores and in vegetative hyphae (Honegger \& Brunner 1981) of the Baeomycetaceae and Leotia, (Figs 2D, 3C, 4B, 5), but also in Ciboria acerina (Corlett \& Elliott 1974). Glycogen, an important storage product of various asco- and basidiomycetes, has so far been detected by cytological techniques in several, not closely related asco- and basidiolichens, but it seems to be absent in lichen mycobionts with either Lecanora-, Peltigera-, Teloschistes-, Rhizocarpon- and Pertusaria-type asci (Honegger \& Brunner 1981, Honegger $1982 b, c)$. Secondly, the differences in phycobiont preference between the Baeomycetaceae and the Cladoniaceae and other members of the Lecanorineae. Considerable differences in cell wall structure and composition were noted with cytological, cytochemical and chemical techniques in different groups of lichen phycobionts (Honegger 1982a, b). Cellulosic walls, which may under certain circumstances be penetrated by mycobiont haustoria, were found in trebouxioid phycobionts (Trebouxia and Pseudotrebouxia species; Hildreth \& Ahmadjian 1981), whereas the highly resistant non-degradable biopolymer sporopollenin was detected in a membrane-like, trilaminar outermost wall layer of the Coccomyxa and Myrmecia phycobionts of the Baeomycetaceae and other asco- and basidiolichens (Honegger \& Brunner 1981, Honegger $1982 a, b$ ).

A preliminary survey of the distribution of these phycobiont cell wall types in correlation with the ascus type and the type of storage products within the Leca-

FIG. 5. Baeomyces rufus. A, Median longitudinal section of a premature ascus; the ring-like apical apparatus is well visible; clusters of glycogen ( $\mathrm{gl}$ ) are seen in the remaining cytoplasm of the ascus; arrows point to several empty asci in various stages of degradation; $\times 10000$. Fixation: Potassium permanganate. B, Empty ascus shortly after ascospore release; dehiscence occurred by bursting of the ascus apex; $\times 15000$. Fixation: Acrolein-glutaraldehyde and osmium. 


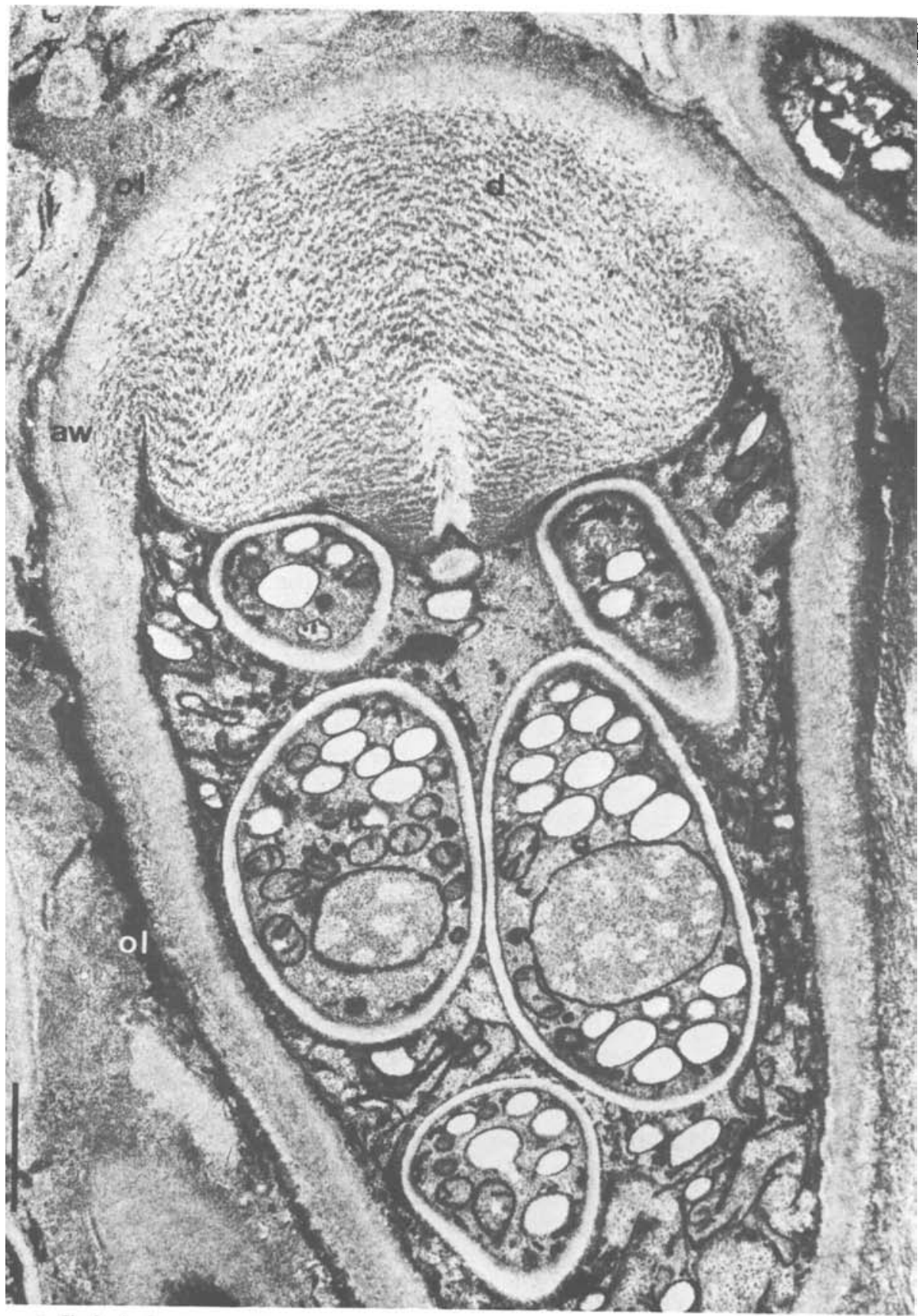

FIG. 6. Cladonia floerkeana, TEM micrograph of a median longitudinal section of the apex of a mature ascus. Inside the ascus wall (aw) and its electron-dense outer layer (ol) is an apical dome containing electron-dense inclusions within an electron-transparent matrix. Accumulations of electron-dense material are seen in the basal parts of the centre of the dome, around a pin-like, electron-transparent zone; $\times 17000$. Fixation: Potassium permanganate. 

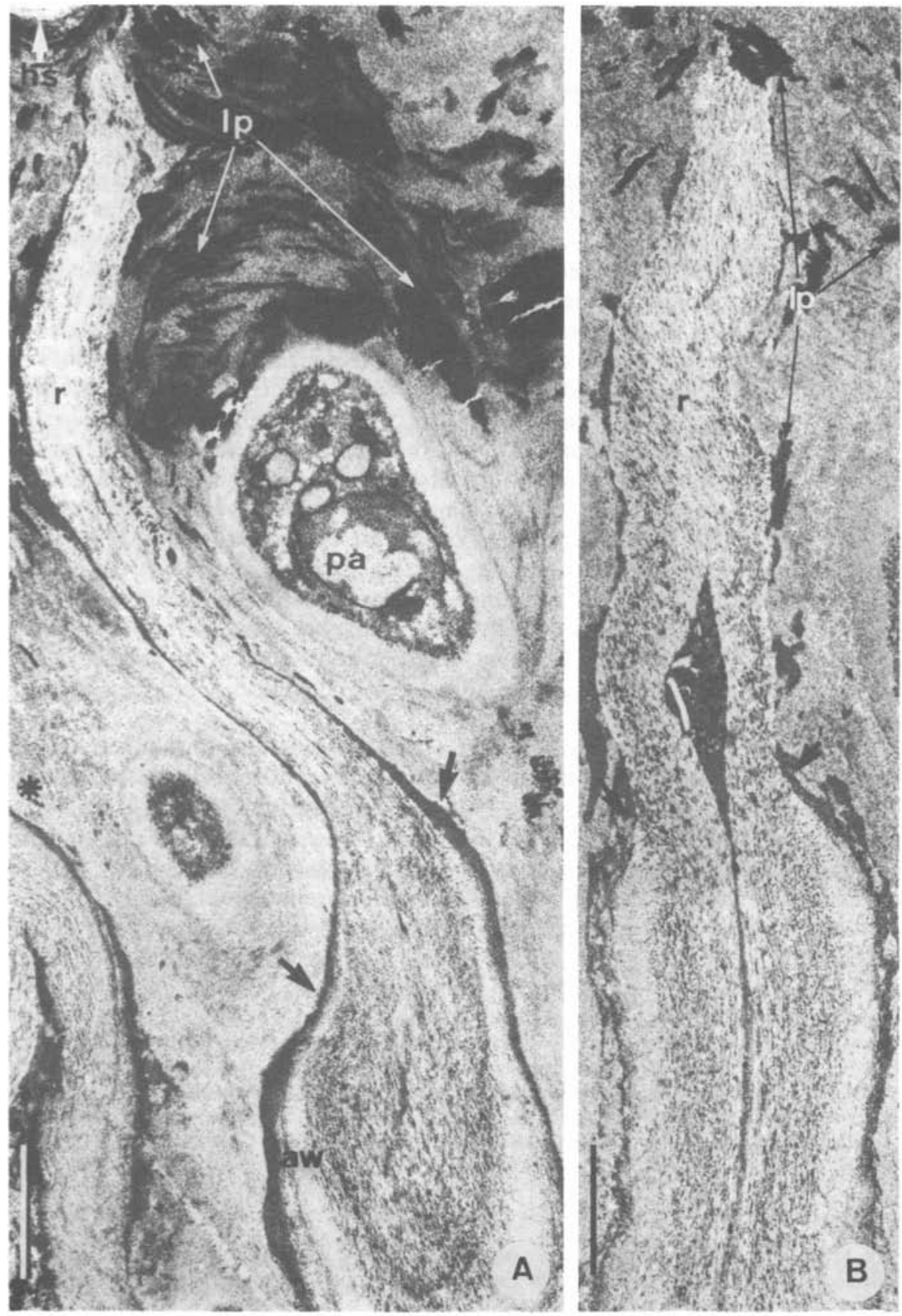

FIG. 7. Cladonia foerkeana, TEM micrographs of longitudinal sections of empty asci after ascospore release. A, Slightly tangential section of an ascus showing the long rostrum ( $r$ ) which reaches the hymenial surface (hs); no gliding site is found between the ascus wall (aw) and the material of the dome; arrows point to the broken ascus wall; the amorphous, electron-dense outer wall layer is smeared over the basal part of the rostrum; high amounts of electron-dense lichen products (lp) crystallized in leaflet-like pattern are seen over the paraphysis (pa); the asterisk indicates the apex of a mature ascus (tangentially sectioned), demonstrating the distance between the tip of the ascus and the hymenial surface, $\times 17000$. B, Median longitudinal section of the empty ascus with its rostrum ( $r$ ); the arrows point to the broken ascus wall and its outer layer; $\times 17000$. Fixation: Potassium permanganate. 
norales strongly indicates the probability of defined phycobiont preferences within natural groups of lecanoralean mycobionts (Honegger, 1982b). The Cladoniaceae, for example, and the majority of other mycobionts with Lecanora-type asci, are symbiotic with trebouxioid phycobionts with cellulosic walls, and they do not produce glycogen particles. The Baeomycetaceae, with their Leotia-type asci, are symbiotic with sporopollenin-containing Coccomyxa and Myrmecia phycobionts, and their vegetative and generative hyphae are rich in glycogen, a combination which is highly atypical for members of the Lecanorineae sensu Henssen \& Jahns (1973; reviewed by Honegger 1982b). It has to be pointed out that this view of phycobiont preference within natural groups of lecanoralean mycobionts does not contradict the statement of Santesson (1953) that 'lichen systematics based on algal characteristics is as unnatural as, e.g., a system of Uredinales based on characters from the host plants'. Only within the evolved, foliose and fruticose members and in many crustose groups of the Lecanorales can the tendency be observed that natural groups of mycobionts are symbiotic with particular types of phycobionts. No such relationships can so far be seen within other orders of the lichenized fungi like the Caliciales or Verrucariales, and in the Graphidales and Gyalectales it is even uncertain whether the mycobiont-phycobiont relationship is a specific one, since many different algae may be found in the poorly organized thalli. It has to be noted, however, that our knowledge of the cytological and biochemical aspects of the mycobiont-phycobiont relationship in different groups of lichens is still very poor.

The transfer of the Baeomycetyceae from the Lecanorales to the Helotiales by Chadefaud (1960) appears, on the basis of the present data on ascocarp otogeny (Letrouit-Galinou 1966, 1968, Jahns 1970) and on the fine structure of the vegetative and generative parts of these lichens, as a consistent step towards a natural classification. It is highly probable that the Baeomycetaceae are not the only lichenized members of the Helotiales. The similarities in ascus structure, function and staining properties in the Baeomycetaceae and the Trapeliaceae, 'a family with no clear relationships' (Poelt 1974), and in some members of the Lecideaceae and Lecanoraceae were described by Hertel (1970) and Honegger (1982c). These groups deserve further investigation.

I am very grateful to Dr D. L. Hawksworth for critically reading and improving the English of this manuscript, and to lic.phil. Beatrice Irlet, Dr E. Horak, and Dr P. M. Jorgensen for kindly providing me with fresh ascocarps of Leotia lubrica.

\section{REFERENCES}

Barr, M. E. (1976) Perspectives in the Ascomycotina. Mem. N.Y. bot. Gdn 28: 1-8.

Bellemère, A. (1977) L'appareil apical de l'asque chez quelques discomycètes: Étude ultrastructurale comparative. Revue mycol. 41: 233-264.

Bellemère, A. \& Letrouit-Galinou, M. A. (1981) The lecanoralean ascus: an ultrastructural preliminary study. In Ascomycete Systematics (D. R. Reynolds, ed.): 54-70. New York, Heidelberg, Berlin: Springer.

Chadefaud, M. (1960) Les végétaux non vasculaires (Cryptogamie). In Traité de Botanique Systématique (M. Chadefaud and L. Emberger, eds): 524-529, 543-545, 639-640. Paris: Masson.

Chadefaud, M. (1973) Les asques et la systématique des Ascomycètes. Bull. trimest. Soc. mycol. Fr. 99: 127-170.

Corlett, M. \& Elliott, M. E. (1974) The ascus apex of Ciboria acerina. Can. J. Bot. 52: 1459-1463. 
Hawksworth, D. L. (1978) The taxonomy of lichen forming fungi: reflections on some fundamental problems. In Essays in Plant Taxonomy (H. E. Street, ed.): 211-243. London, New York: Academic Press.

Henssen, A. \& Jahns, H. M. (1973) ["1974"] Lichenes. Eine Einführung in die Flechtenkunde. Stuttgart: Thieme.

Hertel, H. (1970) Trapeliaceae, eine neue Flechtenfamilie. Vortr. Ges. Geb. Bot. [Ber. dtsch. bot. Ges.] n.f. 4: 171-185.

Hildreth, K. C. \& Ahmadjian, V. (1981) A study of Trebouxia and Pseudotrebouxia isolates from different lichens. Lichenologist 13: 65-86.

Honegger, R. (1977) Development and function of the ascus apex in some Lecanorales (lichenized fungi). In Second Mycological Congress Abstracts (H. E. Bigelow \& G. E. Simmons, eds); 302. Tampa: IMC-2 Inc.

Honegger, R. (1978a) Licht- und elektronenoptische Untersuchungen an Flechten-Asci vom Lecanoratyp. Dissertation, Universität Basel.

Honegger, R. (1978b) The ascus apex in lichenized fungi 1. The Lecanora-, Peltigera- and Teloschistestypes. Lichenologist 10: 47-67.

Honegger, R. (1980) The ascus apex in lichenized fungi II. The Rhizocarpon-type. Lichenologist 12: $157-171$.

Honegger, R. (1982a) Cytological aspects of the triple symbiosis in Peltigera aphthosa. F. Hattori bot. Lab. 52: 379-391.

Honegger, R. (1982b) Ascus structure and function, ascospore delimitation, and phycobiont cell wall types associated with the Lecanorales (lichenized ascomycetes). F. Hattori bot. Lab. 52: 417-429.

Honegger, R. (1982c) The ascus apex in lichenized fungi III. The Pertusaria-type. Lichenologist 14: 205-217.

Honegger, R. \& Brunner, U. (1981) Sporopollenin in the cell walls of Coccomyxa and Myrmecia phycobionts of various lichens: an ultrastructural and chemical investigation. Can. f. Bot. 59: 2713-2734.

Jahns, H. M. (1970) Untersuchungen zur Entwicklungsgeschichte der Cladoniaceen unter besonderer Berücksichtigung des Podetienproblems. Nova Hedwigia 20: 1-177.

Jahns, H. M. \& Smittenberg, J. C. (1970) Baeomyces roseus Pers. Ontogenie und Regeneration der Fruchtkörper. Herzogia 2: 79-88.

Jahns, H. M. \& Horst-Iwema, J. R. (1972) Untersuchungen zur Taxonomie der Gattung Baeomyces II. Herzogia 2: 267-276.

Le Gal, M. (1946a) Mode de déhiscence des asques chez les Cookeina et les Leotia et ses conséquences au point de vue phylogénétique. C. r. hebd. Séanc. Acad. Sci., sér. D, 222: 755-757.

Le Gal, M. (1946b) Un pseudoDiscomycète: Leotia batailleana Bress. Bull. Soc. trimest. mycol. Fr. 62: $50-58$

Letrouit-Galinou, M. A. (1966) Recherches sur l'ontogénie et l'anatomie comparées des apothécies de quelques discolichens. Revue bryol. lichén. 34: 413-588.

Letrouit-Galinou, M. A. (1968) The apothecia of the discolichens. Bryologist 71: 297-327.

Letrouit-Galinou, M. A. (1973) Les asques des lichens et le type archaeascé. Bryologist 76: 30-47.

Luttrell, E. S. (1951) Taxonomy of Pyrenomycetes. Univ. Mo. Stud. 24(3): 1-120.

Magne, F. (1946) Anatomie et morphologie comparées des asques de quelques lichens. Revue bryol. lichén. 15: 203-209.

Ozenda, P. \& Clauzade, G. (1970) Les Lichens. Paris: Masson.

Poelt, J. (1974) ["1973"] Classification. In The Lichens (V. Ahmadjian \& M. E. Hale, eds): 599-632. New York \& London: Academic Press.

Santesson, R. (1953) The new systematics of lichenized fungi. In Proceedings of the 7th Botanical Congress, Stockholm 1950 (H. Osvald \& E. Ảberg, eds): 809-810. Stockholm: Almquist \& Wiksell.

Santesson, R. (1954) The general taxonomy of lichenized fungi. In Congrès international de Botanique, 1954, Rapports et communications, sér. 18: 9-12. Paris: André. 
Downloaded from https:/www.cambridge.org/core. University of Basel Library, on 11 Jul 2017 at 09:04:25, subject to the Cambridge Core terms of use, available at https:/www.cambridge.org/core/terms. https://doi.org/10.1017/S0024282983000055 